MIGRACIONES INTERNACIONALES, VOL. 10, ART. 17, 2019 e-ISSN 2594-0279 http://dx.doi.org/10.33679/rmi.v1i1.2197

\title{
Migraciones, sexualidades e imaginarios transnacionales. Mujeres peruanas en Buenos Aires y varones mexicanos en Chicago
}

\section{Migrations, Sexualities and Transnational Imaginaries. Peruvian Women in Buenos Aires and Mexican Men in Chicago}

Carolina Rosas ${ }^{1}$ y Cecilia Gayet ${ }^{2}$

\section{RESUMEN}

Se analizan imaginarios y rumores sobre la vida sexual de los migrantes que circulan en las comunidades transnacionales, con base en estudios cualitativos con varones mexicanos en Chicago, Estados Unidos, y mujeres peruanas en Buenos Aires, Argentina. Los hallazgos sugieren que en los movimientos latinoamericanos contemporáneos los imaginarios y rumores transnacionales son producto de las tensiones entre la transformación y el control social. Expresan las inquietudes que surgen ante la posibilidad de que, durante el proceso migratorio, se cuestionen las fronteras normativas impuestas por la organización heteropatriarcal de la sexualidad y del género, y por las construcciones raciales y la estructura de clases.

Palabras clave: 1. migraciones, 2. sexualidades, 3. Imaginarios y rumores transnacionales, 4. Latinoamérica.

\section{ABSTRACT}

This article analyzes imaginaries and rumors about the sexual life of migrants that circulate in transnational communities, through a qualitative approach on Mexican men in Chicago (United States) and Peruvian women in Buenos Aires (Argentina). The findings suggest that in contemporary Latin American mobilities, transnational imaginaries and rumors are the product of tensions between social transformation and control. They express concerns about the possibility of transgressing the limits imposed by the heteropatriarchal organization of sexuality and gender, and by racial constructs and class structure.

Keywords: 1. migration, 2. sexuality, 3. transnational imaginaries and rumors, 4. Latin America.

Fecha de recepción: 17 de julio 2017

Fecha de aceptación: 13 de junio 2018

\footnotetext{
${ }^{1}$ Universidad de Buenos Aires, Argentina, rosas.carol@gmail.com, https://orcid.org/00000003-0903-5595

2 Facultad Latinoamericana de Ciencias Sociales (FLACSO), México, cgayet@flacso.edu.mx, https://orcid.org/0000-0003-3080-8089
} 


\section{INTRODUCCIÓN}

En las comunidades transnacionales circulan rumores basados en imaginarios que conforman sistemas de referencias que otorgan diferentes sentidos a la migración y la dotan de una serie de atributos. Es conocido, por ejemplo, que entre los migrantes y sus familias permanecen latentes imaginarios positivos sobre las posibilidades laborales que ofrecerían los países de destino y el ascenso social consecuente, con relativa independencia de las evidencias. Ahora bien, los imaginarios que acompañan los procesos migratorios no sólo exhiben claves económico-laborales, sino también de otros tipos, como las sexuales. En efecto, las comunidades difunden imágenes y supuestos sobre la vida sexual de quienes migran y sobre las formas en que se experimenta la sexualidad en las sociedades de destino de la migración. No se trata de un tema irrelevante para las comunidades transnacionales, dado que se le dedica tiempo de reflexión, se perturban sentimientos y vínculos afectivos, ocasionándose trastornos tanto en quienes se van, como en quienes se quedan.

El objetivo de este artículo es analizar los contenidos de los imaginarios que circulan al interior de las comunidades transnacionales y que refieren a las prácticas sexuales de los migrantes adultos heterosexuales, tanto de varones como de mujeres ubicados en Norte y Sudamérica. Particularmente nos interesa explorar el rasgo erotizado de la figura del migrante, su difusión en la forma de rumores transnacionales y la tensión entre regulación y transformación social que los mismos expresan. También reflexionamos sobre la función de estos imaginarios y rumores, dirigida a advertir -en su doble acepción de revelar y prevenir- las prácticas que cuestionan morales hegemónicas asociadas con la familia y la exclusividad sexual, con la dominación sobre la mujer y con el trabajo productivo, entre otras.

Cabe mencionar que los imaginarios sociales pueden ser comprendidos como "múltiples y variadas construcciones mentales (ideaciones) socialmente compartidas de significancia práctica del mundo, en sentido amplio, destinadas al otorgamiento de sentido existencial" (Baeza, 2011, p. 33). Son un conjunto de repertorios con los que una sociedad o grupo sistematiza y normativiza las imágenes de sí mismo, lo cual involucra también a los modos en que esa sociedad se proyecta hacia lo diferente (García Canclini, 1997). Es decir, son construcciones simbólicas a las cuales los sujetos recurren para interpretar y otorgar sentido a lo que sucede, a los demás y a sí mismos. Según Escobar Villegas (2000):

[...] un imaginario, es un conjunto real y complejo de imágenes mentales, independientes de los criterios científicos de verdad y producidas en una sociedad a partir de herencias, creaciones y transferencias relativamente conscientes; conjunto que funciona de diversas maneras en una época determinada y que se transforma en una multiplicidad de ritmos. Conjunto de imágenes mentales que se sirve de producciones estéticas, literarias y morales, pero también políticas, científicas y otras, como de diferentes formas de memoria colectiva y de prácticas sociales para sobrevivir y ser transmitido (Escobar Villegas, 2000, p. 113). 
Se trata entonces de imaginarios en plural, ya que se refieren a tiempos históricos específicos y, en tanto que sociales, son colectivos. Además, son reales en la medida en que pueden intervenir sobre los comportamientos, con independencia de la realidad de sus contenidos (Escobar Villegas, 2000). En este sentido, según Fressard (2006) los imaginarios sociales son un "magma" de significaciones sociales encarnadas en instituciones del Estado, la familia, educativas, religiosas, políticas, etcétera. No obstante, toda sociedad contiene en sí misma una potencia de alteridad, porque conjuga una estabilización relativa de un conjunto de instituciones con una dinámica que impulsa su transformación. Así, señala Escobar Villegas (2000), las imágenes provienen de distintas fuentes del pasado o se generan por las condiciones presentes y se transmiten en la vida cotidiana; y -lo que resulta fundamental- pueden transformarse y tener distintas funciones, ya sea justificar a las sociedades o ponerlas en cuestión.

El rumor es uno de los repertorios comunicativos de los imaginarios; el mismo refiere a lo secreto, lo no dicho y los miedos colectivos, así como a las utopías, las esperanzas, lo verosímil de una época y de un contexto cultural, el pensamiento social y los imaginarios sociales (Zires, 2009). Los rumores se pueden comprender como "afirmaciones en circulación sobre información instrumentalmente relevante y no verificada que emergen en un contexto de ambigüedad, peligro o potencial amenaza, y que funcionan ayudando a la gente a dar sentido y manejar el riesgo" (DiFonzo \& Bordia, 2007, pp.1-2). Por ello, al igual que los imaginarios, los rumores no deben ser comprendidos en términos de verdad o falsedad. Más bien, dice Rouquette (2009), el valor pragmático del rumor radica en la "advertencia" que el mismo puede suscitar.

En este escrito hemos puesto especial atención en los rumores que transitan por sobre las fronteras de los Estados nacionales, los cuales dan cuenta de los imaginarios construidos en el marco de los procesos migratorios. Hemos priorizado aquellos de tipo impersonal que refieren a colectivos (los varones migrantes o las mujeres migrantes) antes que a eventos específicos o personas, y que suelen ser encabezados (explícita o implícitamente) por la expresión "se dice que" o sus diversas sinonimias. ${ }^{3}$

Para cumplir los objetivos retomamos resultados de investigaciones cualitativas conducidas con dos grupos de migrantes latinoamericanos: a) mexicanos que residen en Chicago, Estados Unidos, y b) peruanos que viven en Buenos Aires, Argentina. Cabe indicar que Estados Unidos es el principal receptor de migrantes latinoamericanos, mientras que Argentina es el tercero en importancia.

Para la primera investigación señalada, entre los años 2001 y 2002 se realizaron 48 entrevistas a profundidad (a 27 varones y 21 mujeres) en el lugar de origen (municipio de

\footnotetext{
${ }^{3}$ Cabe señalar que el rumor es diferente al chisme. Este último refiere a asuntos privados de individuos específicos. Si bien nuestro artículo refiere a rumores, haremos referencia al chisme cuando citemos estudios específicos sobre el mismo.
} 
Naolinco, estado de Veracruz, México) y en el de destino (ciudad de Chicago, estado de Illinois, Estados Unidos). En lo que respecta a los migrantes de origen peruano entrevistados en Buenos Aires, se realizaron 45 entrevistas a profundidad (a 19 varones y 26 mujeres) entre 2005 y 2007 y, posteriormente, cinco entrevistas a mujeres peruanas durante los años 2013 y 2014. Para este artículo seleccionamos los casos de mujeres y varones que estaban en unión conyugal (sea ésta civil, religiosa o de hecho) al momento de la migración suya o de su cónyuge. Las investigaciones compartieron perspectivas teóricas, intereses temáticos e instrumentos metodológicos, que fueron adaptados a cada contexto. En todos los casos se hicieron entrevistas biográficas ${ }^{4}$ que permitieron reconstruir retrospectivamente el pasado de los entrevistados.

Los dos flujos migratorios estudiados nacieron durante la última década del siglo $\mathrm{XX}^{5}$ Por lo tanto, al momento en que se realizaron los trabajos de campo ambos contaban con escasa antigüedad migratoria y con redes en proceso de consolidación. Entre los mexicanos prevalecía la migración de varones rurales, mientras que entre los peruanos predominaban los movimientos de mujeres urbanas. En los dos casos sobresalían las razones laborales y económicas. Ambos estaban constituidos por población joven (en edades laborales), de escolaridad media, que se insertaba en los países de destino en ocupaciones no calificadas. No obstante, los contextos presentaban condiciones migratorias sumamente diferentes. A diferencia de lo que sucedía en el Norte, los peruanos encontraban en el Sur el mismo idioma, fronteras menos vigiladas, y transitaban dentro de un mercado regional (MERCOSUR) que favorecía relativamente la libre movilidad de los ciudadanos de los Estados parte y asociados. Asimismo, los flujos que se dirigen a la Argentina no encuentran las restricciones ni la peligrosidad que afectan los movimientos hacia Estados Unidos. Estos aspectos, sumados a las oportunidades diferenciales que brindaban los mercados de trabajo a varones y mujeres, contribuyen a comprender por qué el mexicano es un flujo masculinizado y el peruano, uno feminizado.

En cuanto a la estructura del artículo, en la sección siguiente se presenta el recorrido de los estudios que en el campo migratorio latinoamericano han abordado la sexualidad, sin pretensión de exhaustividad. Seguidamente se analizan los imaginarios construidos

\footnotetext{
${ }^{4}$ La entrevista biográfica se interesa por las historias y experiencias de la vida cotidiana de las personas (Bron \& Thunborg, 2015). La persona entrevistada construye su propia historia narrando su vida pasada tal como la recuerda y como desea que el otro la conozca, a partir de pautas dadas por el entrevistador (Atkinson, 1998).

5 En el caso de Veracruz, la migración creció a la luz de la crisis de los precios del café y de la caña de azúcar. De allí migraron pequeños propietarios, ejidatarios y peones que no lograban emplearse en las cosechas. Por otra parte, la migración de peruanos hacia Argentina estuvo empujada principalmente por los efectos de la aplicación de políticas neoliberales en Perú que elevaron la precariedad laboral y el desempleo, así como por una crisis institucional generalizada. Para abundar en estos aspectos consúltese Rosas (2008 y 2010).
} 
alrededor de los escenarios de destino, en lo que concierne a las costumbres y las prácticas asociadas a la sexualidad. Luego nos dedicamos a los rumores que circulan en relación a la vida sexual de las y los migrantes, así como a las características imaginadas de los sujetos con los que supuestamente se relacionarían. También dedicamos un apartado a observar las particularidades de los imaginarios sobre las mujeres migrantes. Finalmente, se presenta una discusión sobre la función de los imaginarios y de los rumores transnacionales. ${ }^{6}$

\section{ANTECEDENTES EN EL ESTUDIO DE LAS SEXUALIDADES Y LAS MIGRACIONES DE LATINOAMERICANOS}

Tanto la sexualidad como la migración son procesos sociales, y en tanto que tales, incluyen actos, relaciones y significados. En cuanto a la primera, "[1]a sociedad es la instancia principal de la producción de la sexualidad humana" (Bozon, 2009, p. 7). Es decir, los seres humanos no nos comportamos sexualmente por instinto, sino que aprendemos a comportarnos sexualmente; y, en tanto que construcción cultural, la sexualidad humana implica la coordinación de una actividad mental, una interacción social y de una actividad corporal (Bozon, 2009). La sexualidad se construye en contextos sociales y culturales específicos, y en términos generales puede decirse que en ambas sociedades de origen de los migrantes, mexicana y peruana, está caracterizada por el énfasis en normas heteropatriarcales y de exclusividad sexual entre las personas unidas, al igual que en las sociedades de destino, argentina y estadounidense. ${ }^{7}$

La dimensión de la sexualidad estuvo relativamente invisibilizada en el campo de los estudios de migración hasta épocas recientes cuando la vinculación entre sexualidad y migración se convirtió en un campo de estudio en crecimiento (Manalansan, 2006; Hernández-Hernández, 2015). Siguiendo la tendencia de otros lugares del mundo, las primeras vinculaciones entre la sexualidad y las migraciones latinoamericanas fueron elaboradas por especialistas preocupados por la expansión de la epidemia del VIH.

Muchos de esos estudios se hicieron desde la perspectiva de la salud pública, aunque con el tiempo se fueron incorporando otras perspectivas donde sobresale la de género, y se abordaron las conductas sexuales de los migrantes en Estados Unidos, así como las estrategias de prevención y las consecuencias sobre las esposas de los migrantes, entre otros aspectos (Bronfman \& Minello, 1999; Salgado de Snyder, 1998; Hirsch, 1999; Gayet, Magis \& Bronfman, 2000; Magis-Rodríguez, Gayet, Negroni, Leyva, BravoGarcía, Uribe y Bronfman, 2004; Caballero, Leyva-Flores, Ochoa-Marín, Zarco \& Guerrero, 2008; Hidalgo, García, Flores, Castañeda, Lemp y Ruiz, 2008; Martinez-Donate, Hovell, Rangel, Zhang, Sipan, Magis-Rodríguez y González-Fagoaga, 2015; entre otros).

${ }^{6}$ Los nombres de las y los entrevistados han sido modificados para resguardar su anonimato. Por otra parte, las palabras textuales de nuestros entrevistados se introducen en el formato cursiva para distinguirlas del resto del escrito.

${ }^{7}$ Para abundar en la dimensión de heteropatriarcado, véase Hoagland (2002). 
El afianzamiento de la perspectiva de género en el campo migratorio fue dando lugar a estudios que, por fuera del enfoque epidemiológico, incluyeron análisis de distintas dimensiones de la vida sexual de las y los migrantes. En esa línea se analizaron las características de las relaciones sexuales mantenidas en los países de destino, las prácticas de control de la sexualidad femenina a la distancia, y los efectos sobre la vida de las mujeres que quedan en los lugares de origen, entre otros aspectos (D'Aubeterre Buznego, 2000; Hirsch, 1999; Pedone, 2003; Rosas, 2008; Caballero, et al., 2008; González-López, 2009; Ochoa-Marín, Cristancho-Marulanda \& González-López, 2011; Rivera-Heredia, Obregón Velasco \& Cervantes Pacheco, 2013, entre otros).

Entre los estudios dedicados a analizar los procesos subjetivos asociados a la sexualidad, encontramos el de Skolnik, De La Vega \& Steigenga (2012), donde se analizan los chismes transnacionales que producen distintas consecuencias en las mujeres guatemaltecas esposas de migrantes, así como los factores que intensifican la circulación de chismes. Cabe señalar que los chismes y rumores transnacionales conforman un interesante y rico ámbito de estudio escasamente abordado por los estudios de migración, de modo que nuestro análisis procura realizar un aporte a dicho ámbito.

También ha habido interés por evidenciar procesos de cambio en la vida sexual de las mujeres migrantes: mexicanas en Estados Unidos (González-López, 2009), peruanas en Buenos Aires (Rosas, 2010) y colombianas en España (Gonzálvez, 2014), entre otras. Mientras que otros abordajes se han interesado por la vinculación entre migración, sexualidad y violencia (Pérez Oseguera, Coppe Gorozope, Pérez Petrone \& Trujillo Viruega, 2008; Delgadillo Guzmán, Vargas Cortez, Nievar, Argüello Zepeda \& González Villanueva, 2013).

Los estudios sobre masculinidades (Rosas, 2008; Quispe-Lázaro \& Muñoz-Laboy, 2008; Cohen, 2015) han puesto el acento en las emociones y relaciones afectivo-sexuales de los varones migrantes en Estados Unidos y en las formas que ellos las explican e intentan aminorar su impacto sobre sus esposas y familias, entre otros aspectos. Por su parte, Quispe-Lázaro y Muñoz-Laboy (2008) mostraron que algunos varones se ven obligados a tener relaciones sexuales a cambio de dinero por razones económicas, pero también como un mecanismo para paliar la soledad.

Otro aspecto que ha tenido relativa visibilidad es aquel interesado en la relación entre los procesos migratorios y la llamada "industria del sexo". Se han analizado, por ejemplo, las trayectorias de trabajadoras sexuales brasileñas que se unieron con varones italianos (Piscitelli, 2008), así como los proyectos migratorios y situación de las mujeres peruanas y colombianas que trabajan en el comercio sexual en una zona fronteriza del Ecuador (Ruiz, 2008).

Más recientemente, la vinculación entre el campo migratorio y los estudios LGBTQ ha permitido cuestionar algunos supuestos en torno a la familia, la reproducción heterosexual 
y el matrimonio que abundan en la bibliografía sobre migración y género (Stang, 2015), los cuales han tendido a concebir a la sexualidad en un sentido heteronormativo. Para Manalansan (2006), en la investigación sobre migraciones la sexualidad ha estado relegada al análisis de la reproducción, de la abstinencia forzada causada por la migración y del abuso sexual o la violación. Ha habido discusiones muy limitadas sobre la sexualidad y el placer. Este autor nos invita a ir más allá del agente migrante trabajador y a poner de relieve el deseo y el placer buscado por los y las migrantes. De igual manera, GonzálezLópez (2009) señala la necesidad de centrar la mirada en los usos y significados del cuerpo, en el erotismo y el deseo.

En consonancia con lo anterior, muchos estudios abogan por el reconocimiento de que las identidades y las prácticas sexuales son factores centrales de los proyectos migratorios (Pichardo Galán, 2003; Córdova Quero, 2014; García y Oñate Martínez, 2008; Cribari, Pandolfi \& Torre, 2012; entre otros) y varios de ellos enfatizan la necesidad de incorporar una perspectiva interseccional en el abordaje de la experiencia migrante (Luibhéid \& Cantú, 2005; Manalansan, 2006), lo cual procuraremos realizar en estas páginas.

Cabe indicar que la interseccionalidad es una perspectiva analítica que pondera el abordaje de la interacción entre las categorías sociales del género, las construcciones raciales, la clase social y otros principios socioculturales de clasificación en la vida de las personas y en las prácticas sociales, visibles también en las convenciones institucionales y las ideologías culturales, así como las consecuencias de estas interacciones (Stolcke, 2010). De hecho, Magliano (2015) señala que los procesos migratorios están conformados por diversos ejes de desigualdades, y que por ello resultan un campo relevante para el análisis teórico y empírico de la interseccionalidad. Es decir, la intersección de las clasificaciones de género, clase, origen nacional, raza, etnicidad, edad y condición migratoria incide en la vida cotidiana de varones y mujeres migrantes, e influye en su acceso a derechos y oportunidades, así como en las situaciones de exclusión o de privilegio que de ellas se derivan, y en las posibilidades de transformación social.

\section{DESTINOS IMAGINADOS}

Las migraciones conllevan la producción y reproducción de imaginarios sobre los lugares de destino, en las que participan tanto los sujetos migrantes como los familiares y allegados. Aun antes de migrar se producen anticipaciones sobre las características del destino, donde no están exentos los imaginarios sobre las prácticas sexuales en ese lugar, las cuales tienden a visualizarse y valorarse como diferentes y lejanas a las costumbres del origen.

Para quienes ven partir a los migrantes, los destinos se representan como espacios socioculturales en los cuales habría más libertad para vincularse sexualmente con otras personas. Blanca, una de las esposas entrevistada en México, explica que en su pueblo se 
dice que los hombres se van porque ya se cansaron de la esposa, de la obligación y se van a ser libres por allá. Por otra parte, el relato de Alicia revela la intriga que las esposas mantienen sobre los comportamientos de sus parejas, y las hipótesis que se tejen sobre la existencia de amplias posibilidades sexuales a disposición de los varones migrantes en Estados Unidos.

[Le digo a mi esposo] "sabrá Dios qué hagan, porque ustedes son hombres y no faltan mujeres..." Dice mi esposo que allá las mujeres hasta los van a buscar a las casas... Quién sabe cómo será eso ¿Las mujeres van a buscar a los hombres o los hombres van a buscar a las mujeres? (Alicia, mexicana, comunicación personal, ${ }^{8} 9$ de mayo de 2001).

Según las entrevistadas, en su pueblo no existe la misma libertad que en Estados Unidos, menos aún para las mujeres. Lorna, cuyo esposo también migró a Estados Unidos, explica que en la localidad de origen: "no somos libres [...] tú, porque la gente no hable de ti, o porque la gente no piense mal, siempre andas bien derechita".

En Perú circulan ideas similares respecto del país de destino, Argentina. Eso se observa en los relatos de los esposos varones que migraron después que sus esposas, como es el caso de Paulo: "[antes de venir, yo pensaba] de repente ella se olvida de mí; esa era mi preocupación [...] allá [en Perú] se dice que hay mucho libertinaje [en Argentina]" (comunicación personal, 11 de marzo de 2006). Así, en el contexto sudamericano se replica la idea de que el destino ofrece mayores posibilidades de relacionamientos sexuales, pero en este caso son las mujeres quienes ganarían libertad al migrar.

Por su parte, los migrantes, quienes efectivamente han conocido los destinos, parecen reforzar el imaginario a través de distintos relatos. Si bien los mexicanos y peruanos entrevistados conviven con paisanos y parientes en los destinos, muchos expresan que ahí no tienen que cuidar sus acciones como lo hacían antes de migrar. Dicen sentirse relativamente anónimos en Argentina y en Estados Unidos; se ha aminorado su preocupación por el qué dirán, ya que ahora uno hace su vida y no le importa lo que hace el de al lado. Este es un aspecto en el que coinciden gran parte de los estudios dedicados a las migraciones LGBTQ. Por ejemplo, Cribari et al. (2012) señalan que sus entrevistados de origen uruguayo refieren que las ciudades de destino tienen estilos de vida modernos, que allí no sienten la intromisión de otros en su vida privada, y que se sienten anónimos.

Los peruanos marcan mayores contrastes entre "la sociedad" de destino y su lugar de origen, que los mexicanos. Daniel, por ejemplo, expresa que la cultura [argentina] es un poco más liberal (comunicación personal, 6 de

\footnotetext{
${ }^{8}$ La expresión "comunicación personal" ha sido introducida junto a los extractos de las entrevistas por exigencia del estilo de citación. Como se ha dicho en la introducción, este estudio es el resultado de investigaciones que utilizaron la técnica de entrevista a profundidad en el marco de diseños metodológicos de tipo cualitativo.
} 
diciembre de 2006); Beatriz menciona con molestia que no hay pudor en Argentina, mientras que Rudy y Emma enfatizan que en Perú hay más respeto. Algunos se sorprenden ante los programas televisivos en los que abiertamente se habla de sexualidad y donde se muestran cuerpos semidesnudos. También suele afirmarse que, a diferencia de lo que ocurre en Perú, en Argentina los varones son menos machistas, y que la mujer tiene los mismos derechos que el hombre. Les sorprende, además, observar que algunas mujeres tienen amigos varones y sus esposos no se los impiden. ${ }^{9}$

Estos relatos dan cuenta de la existencia de estereotipos que dicotomizan y sustancializan supuestas diferencias socioculturales entre los orígenes y los destinos. A estos dos últimos se los asocia con imágenes antagónicas en relación al pudor, la libertad, el respeto y el anonimato. Así, las fronteras geopolíticas son grandes productoras de fronteras simbólicas con importantes consecuencias en la vida cotidiana de los sujetos, migrantes y no migrantes.

Si bien los imaginarios existen y su análisis es relevante en la medida que producen múltiples efectos, es necesario no perder de vista su carácter simbólico y recordar las muchas investigaciones que contradicen las imágenes antagonistas. Asimismo, sin negar la existencia de contrastes socioculturales entre los países, nosotras compartimos los cuestionamientos a los análisis que pretenden jerarquizar contextos migratorios basándose en diferencias "objetivas" en las formas y significados de la sexualidad (Cantú, 2009; Vidal Ortiz, 2013).

Así, cuestionamos los análisis que desde un enfoque de género piensan a los contextos de origen como tradicionales y opresivos, y a los de destino como espacios modernos y emancipadores de la mujer, invisibilizando la heterogeneidad que los caracteriza y olvidando que en los destinos los migrantes experimentan una gama diversa de discriminaciones y controles en distintos ámbitos de sus vidas (Rosas, 2010). Tampoco podemos olvidar que los imaginarios que enfatizan contrastes culturales o étnicos suelen ser producidos y reproducidos por los discursos académicos, políticos y religiosos, por los medios de comunicación y por las autoridades de turno. Es decir, no es casual que estos imaginarios estén extendidos entre las/los entrevistados.

9 Entre los mexicanos hay escasos relatos que refieren a los gringos. Con éstos, los intercambios cotidianos se circunscriben a cuestiones laborales puntuales, mientras que los momentos de ocio se comparten con los paisanos. El idioma es una importante barrera que también puede impedir observar la televisión en inglés. 


\section{La erotización de la figura del migrante}

En algunos países de América Latina existe un refrán que dicta que "en casa del jabonero quien no cae, resbala". ${ }^{10}$ Uno de los entrevistados peruanos, Martín, lo enunció para sugerir que las personas en unión conyugal que migran a un lugar con una imaginada sexualidad libre, inevitablemente mantendrán alguna relación sexual extramatrimonial (pisarán el palito), contradiciendo así la norma monogámica.

Acá [en Argentina] es "la casa del jabonero: el que no cae, resbala". Mi señora tiene muchos familiares acá, primas, cantidad; no hay ninguna que no haya pisado el palito, no hay ninguna que no haya tenido un problema de infidelidad. Siguen con sus esposos en Perú muy tranquilos. Cuando yo viajo allá, todas me tienen miedo; dicen: "a éste se le va a salir la lengua". Pero yo soy muy varón, no sé nada de nada (Martín, peruano, comunicación personal, 26 de septiembre de 2007).

Es decir, junto al supuesto de que los destinos (Estados Unidos y Argentina) son más liberales en materia sexual que los lugares de origen, se supone también que los migrantes aprovechan las oportunidades para ejercer la sexualidad por fuera de la monogamia normativa. En otras palabras, hay un arraigado imaginario erotizado de la figura del migrante, sea este varón o mujer, que parece sentenciado a resbalar o caer. En ese marco, muchos entrevistados pronostican que las y los migrantes abandonarán a sus esposas o esposos que quedaron en el lugar de origen.

Como se observa, la concepción del lugar de destino como un espacio con poderes modificatorios de la conducta sexual del migrante es una idea compartida por los entrevistados mexicanos y peruanos. Es así que cuando alguien transita hacia una sociedad que se imagina con menos controles sociales, generalmente se supone que intensificará su actividad sexual.

Según Mario, en su pueblo mexicano todos dicen que quien se marcha a Estados Unidos, lo hace para buscar mujeres. Blanca acota que "las mujeres que tienen sus esposos allá [en EU] o que piensan irse, pues el temor de ellas es que [ellos] ya no regresen [...] porque muchos no han regresado; se han casado allá" (comunicación personal, 5 de junio de 2002).

Por su parte, los esposos que quedaron en Perú mientras sus mujeres migraron a la Argentina, experimentaban preocupaciones similares y recibían con frecuencia burlas por la posibilidad de ser abandonados por ellas (Rosas, 2010). ¿Vos crees que tu mujer te va a llevar, huevón? Eso me decían mis amigos, relata Rudy (comunicación personal, 10 de octubre de 2005). Mientras que a Sara, una mujer que migró a la Argentina antes que su esposo, sus familiares y amigos en Perú le decían “iqué valiente [que no abandonaste a tu

${ }^{10} \mathrm{El}$ mismo, en su sentido literal indica que donde se fabrica jabón (la casa del jabonero) el suelo está resbaloso y, por eso, quien por allí camine seguramente se caerá o resbalará. 
marido]! Porque mayormente las que se van, se consiguen otro marido, se olvidan de los hijos" (comunicación personal, 15 de mayo de 2006).

Si bien en los discursos de los familiares que se quedaron en el lugar de origen se observa la afirmación de este imaginario que supone una intensificación de la actividad sexual en los destinos, las narraciones de los migrantes se observan menos contundentes. Los relatos de estos últimos oscilan entre aquellos que parecen reforzar el imaginario y otros que lo cuestionan rotundamente, como veremos a continuación.

Un ejemplo de quienes contribuyen a afirmar el imaginario lo encontramos en Beto, uno de los pioneros en su pueblo de la emigración hacia Estados Unidos, quien en medio de su dolor por emprender el largo y peligroso viaje se despidió de sus amigos diciendo en forma de broma "ahi les saludo a las gringas". Otro ejemplo lo encontramos en Martín, citado al comienzo de este apartado, quien enfáticamente generaliza que todas las migrantes emparentadas con su esposa han "tenido un problema de infidelidad" (comunicación personal, 26 de septiembre de 2007). Mientras que Emma también refuerza el imaginario al argumentar que no es su generación la que se ha tomado mayores libertades sexuales en Argentina, sino que las jóvenes que están viniendo ahora son un desastre, porque vienen, trabajan y se van a bailar, se olvidan de los hijos en Perú.

Quienes aseguran que las y los migrantes viven con mayor libertad su sexualidad en los destinos, tienden a explicarlo diciendo que se trata de una necesidad del cuerpo, que se impone a su voluntad. "Aquí el sexo viene siendo... como que casi lo agarras como una necesidad; 'donde tú dices: mi cuerpo lo necesita [...] Lo que tú necesitas es sacar tu necesidad", menciona Beto desde Chicago (comunicación personal, 26 de noviembre de 2001). Cabe señalar que el énfasis en el aspecto corporal-genital procura quitar el elemento afectivo, y así disminuir el ofensivo.

De hecho, los estudios de masculinidad han mostrado que el imaginario sobre el deseo sexual y la imposibilidad de "aguantarse" durante cierto tiempo sin mantener relaciones sexuales, está sostenido en la creencia de que existe una "naturaleza" en los varones que los obliga a mantener relaciones periódicamente. Aunque con menos frecuencia, también entre los peruanos encontramos relatos que reconocen el deseo erótico en la mujer migrante y sugieren su dificultad para "aguantarse". En este sentido Tito, un peruano entrevistado en Buenos Aires, interpreta que al estar alejadas de los esposos "la mujer [migrante] estaba tan ávida de sexo, que no aguantaba" (comunicación personal, 6 de junio de 2007).

En el contexto migratorio, la mayor libertad sexual imaginada para quienes cruzan las fronteras está altamente vinculada al movimiento y a las inquietudes que suscita el nomadismo. Esta idea fue sugerida por Ana, de origen peruano, cuando aseveró que quienes andan por todos lados tienden a ser mujeriegos. De hecho, "los que duermen fuera" son un grupo representado en los discursos históricos mexicanos como quienes tendrían más posibilidades de adquirir infecciones de transmisión sexual (Gayet, 2015). 
Aparecen así distintos tipos de viajeros siendo asociados con comportamientos sexuales "riesgosos". Y la figura del migrante, varón o mujer, se ajusta a esa representación.

A pesar de que como hemos visto algunos migrantes contribuyen con sus relatos a exaltar el imaginario, otros lo cuestionan manifestando malestar e indignación. Varios varones mexicanos cuestionaron la exageración contenida en el mismo y adujeron que eso desmerece su esfuerzo cotidiano, así como los peligros que enfrentaron para llegar a Estados Unidos y el tiempo que le dedican a trabajar para sostener a sus familias.

Al respecto, con una mezcla de tristeza e impotencia, Silvio expresa que "las personas que están de aquel lado [en México] piensan cosas muy distintas a lo que es la realidad aquí... No se dan cuenta, no saben la forma de vivir aquí uno [...] [Mi esposa] me dice: ¡tú andas acá y tú andas allá! Digo, ¡nooo! Y hay veces que ni siquiera salgo por una semana" (comunicación personal, 5 de diciembre de 2001). Hugo también considera que en México dicen de más. Según su percepción, no hay diferencias en el comportamiento sexual de los varones en Estados Unidos y en México en cuanto a tener parejas simultáneas: eso no nomás es aquí [en EU], también allá [en México] lo hacen (comunicación personal, 28 de noviembre de 2001).

Como consecuencia del imaginario descripto, las parejas mexicanas y peruanas que se encuentran separadas por miles de kilómetros dedican mucho tiempo a discutir y a reprocharse mutuamente vía telefónica. Para quienes se reunifican en los destinos tampoco es sencillo superar las sospechas alimentadas por los rumores. Todo ello, además, suele acongojar a los hijos y al resto de la familia, como explica Emma: "mis hijas me llamaban [desde Perú] y me decían: mamá lleva a mi papá porque aquí todos lo joden [...] [Mi hija me decía:] mi papá llora, le dicen que ya tú tienes otro allá, que ya no lo vas a llevar, que no vas a venir nunca” (comunicación personal, 16 de noviembre de 2005).

En síntesis, en las comunidades transnacionales hay un arraigado imaginario erotizado de la figura del migrante. Especialmente entre quienes permanecen en los lugares de origen prevalece la idea de que las y los migrantes dedican muchas energías a su vida sexual, y que ello eleva la probabilidad de que abandonen a sus parejas y familias. Es interesante notar que ese imaginario se replica en dos comunidades transnacionales que no tienen vínculos entre sí y que está adherido tanto a varones como a mujeres migrantes.

Como dijimos en el apartado anterior, el dar cuenta de los imaginarios y de los efectos que ellos producen no implica otorgarle valor de verdad a su contenido ni olvidar su carácter simbólico. En este sentido, si bien la experiencia migratoria puede conllevar cambios en la experiencia sexual de las personas, no se trata de un proceso necesario. Es decir, si bien "es sabido que algunos mantienen una doble vida familiar posibilitada por la distancia" (Pedone, 2003, p. 302), la esencialización del comportamiento sexual de las y los migrantes presente en el imaginario debe ser cuestionada con los mismos argumentos 
que utilizamos para cuestionar la sustancialización del antagonismo entre los contextos de origen y destino.

\section{Sujetos de deseo imaginados}

Los "mercados" afectivos y sexuales a los que acceden los migrantes suelen tener características relativamente homogámicas (Rosas, 2013). Quienes conforman pareja en los destinos lo hacen principalmente dentro de un entorno espacial y sociocultural acotado (Quispe-Lázaro \& Muñoz-Laboy, 2008; Cohen, 2015). Además, no es sencillo para los migrantes vincularse con sujetos de las sociedades de destino, donde se los discrimina de diversas maneras.

Sin embargo, las comunidades transnacionales imaginan otras vivencias. Entre las esposas mexicanas que permanecen en los lugares de origen está arraigada la idea de que los varones migrantes tienen amplias posibilidades de seducir a, y ser seducidos por, mujeres a quienes imaginan guapas, libertinas y disponibles (que se prestan y están a la orden del día).

Asimismo, entre los peruanos observamos un imaginario con características similares. Algunos varones creen que sus esposas migrantes desean a los argentinos porque son lindos, son bonitos. Más específicamente, los rumores difunden que las mujeres peruanas acceden a, y son deseadas por varones argentinos, jóvenes, bellos y con mayores recursos económicos. Imaginarios similares han sido encontrados en otros contextos migratorios (véase Pedone (2003) para el caso de mujeres ecuatorianas en España).

Tanto entre los peruanos como entre los mexicanos entrevistados los imaginarios sobre los sujetos de deseo están configurados por ideas hegemónicas -de género, nacionalidad y construcciones étnico-raciales- que sirven para subrayar su sentido de exclusión. De forma similar a lo señalado por Esguerra Muelle (2014), podemos decir que dichos imaginarios expresan formas sutiles de racismo que van en detrimento de los migrantes, de sus esposos y esposas, así como de sus comunidades transnacionales en general. Esta autora observó "tanto un racismo fenotípico como uno más complejo vinculado a ideas sobre el prestigio (la elegancia), la belleza, o incluso la civilización y la modernidad" (2014, p. 148). Es así que siguiendo a Canessa (2008) podemos decir que en estos imaginarios el deseo sexual de los migrantes es concebido a partir de una estética sensual que también está vinculada a una erótica del poder.

Para finalizar, es importante mencionar que en el caso de las mujeres peruanas en Buenos Aires aparece también en el imaginario la figura de otras mujeres como posibles objetos de deseo. Así, la migración femenina parece incluso poner en cuestión la heterosexualidad normativa. Eso se observa en el relato de Pablo, un migrante peruano. Es notable la forma en que el entrevistado normaliza y amplifica la manifestación de relaciones homoeróticas de mujeres migrantes en espacios públicos. De hecho, sus palabras 
condensan los distintos temas tratados a lo largo de las páginas anteriores: la sociedad de origen aparece descripta como un espacio regulador de las prácticas mientras que el lugar de destino es interpretado como más permisivo respecto a las relaciones entre personas del mismo sexo, y las mujeres migrantes son representadas como quebradoras de las barreras normativas de la sociedad de origen en cuanto al objeto del deseo sexual.

En estos últimos años se nota una tendencia a que muchas mujeres peruanas son lesbianas [...] Ahora ya es casi normal ir a un baile y encontrar a dos mujeres bailando y besándose, no les interesa el resto. Es que esa barrera ya se ha superado, y eso lo han superado acá [en Argentina], porque la sociedad te lo permite también. En Perú era muy difícil (Pablo, peruano, comunicación personal, 8 de mayo de 2006).

\section{Imaginarios similares, pero no iguales: "ellas se ven peor"}

En las secciones anteriores expusimos las principales similitudes encontradas en los imaginarios construidos sobre la vida sexual de los varones migrantes mexicanos en Estados Unidos y de las migrantes peruanas en Argentina. Tanto a unos como a otras se les imagina ávidos por el sexo, y se construyen conjeturas en las que se sostiene que eso afectará su rol laboral, el envío de remesas y sus vínculos familiares. Además, a ambos grupos se los imagina proclives a vincularse con sujetos que reúnen características étnicoraciales representadas como hegemónicas.

Sin embargo, hay diferencias no sutiles entre las imágenes que refieren a unos y otras, ya que los cuestionamientos a las mujeres alcanzan mayor magnitud y virulencia. También Dreby (2009) encontró que los rumores acerca de la mujer llevan a un mayor estigma debido a que sus supuestas "transgresiones" son de carácter moral; en cambio, según la autora, los chismes sobre los hombres sólo son graves cuando su "transgresión" amenaza su papel tradicional como proveedores económicos.

En efecto, a diferencia de lo que sucede con las mujeres, el ejercicio sexual extramatrimonial de los varones suele justificarse. En el marco de nuestras investigaciones encontramos que es común que las esposas de los migrantes mexicanos expliquen este imaginario diciendo "ellos son hombres". Es decir, se los concibe como víctimas de su biología (su cuerpo les demanda tener relaciones sexuales) o como presos de su aprendizaje de género (los hombres no saben aguantarse las ganas, las mujeres sí). Estos imaginarios sobre los varones no sólo se encuentran en contextos migratorios, sino que responden a las construcciones sexo-genéricas relacionadas con la masculinidad y la feminidad heterosexuales en las sociedades latinoamericanas. En términos generales, en esas construcciones las figuras masculinas (padres, esposos, hermanos, etcétera) y femeninas (madres, esposas, hijas, etcétera) son estereotipadas como antagónicas y asimétricas en términos de poder, bajo el supuesto de que los primeros ejercen control 
sobre las segundas, gozan de mayor libertad para relacionarse y ejercer su sexualidad, y fortalecen su dominación mediante la provisión económica.

Dichas construcciones sexo-genéricas también están presentes en Perú y ayudan a comprender la emergencia de los mayores cuestionamientos que reciben las mujeres migrantes peruanas. Como expresan Nyberg Sørensen y Vammen (2016), los imaginarios sobre las estrechas relaciones emocionales madre-hijo se ven confrontados por la migración de estas mujeres, que se alejan geográficamente de sus hijos. Por ello, las madres migrantes procuran reponer su desgaste emocional y estigma social enviando la mayor parte posible de sus ingresos. En efecto, en las entrevistas realizadas en Buenos Aires se relata que luego de trabajar y de cumplir con el envío de remesas, muchas mujeres peruanas salen a divertirse para combatir la soledad y olvidar la dureza de su trabajo cotidiano como empleadas domésticas. De hecho, algunos varones peruanos entrevistados dicen comprender que las mujeres deseen divertirse, porque ellos siempre han hecho lo mismo. Pero precisamente porque trabajar e ir solos a bares era una experiencia atribuida a los varones en Perú, y no a las mujeres, se dice que una vez en Buenos Aires ellas bebian de más y luego 'venía lo que venía'” [tenían relaciones sexuales extramatrimoniales]. Incluso, se relata la presencia de hombres que sacarían ventajas de las migrantes, ya sea quitándoles dinero o acosándolas sexualmente: "detrás de una mujer mareada hay dos o tres hombres que la quieren llevar a cualquier lado”, sentencia Pablo (comunicación personal, 8 de mayo de 2006). En pocas palabras, en este imaginario se reconoce a la mujer como sujeto de deseo, pero también se deja constancia de que ella no sabe cómo manejar "adecuadamente" ese deseo (porque sería inexperta o no le sería propio), y con frecuencia se la subordina a una figura masculina que saca provecho de ella.

En términos comparativos, los relatos que refieren a la actividad sexual de las mujeres migrantes peruanas contienen una mayor carga denigratoria y estigmatizante que la evidenciada respecto de los varones mexicanos. Se dice que algunas se alcoholizan y se las representa bien como mujeres viejas que acosan a jóvenes, o bien como jóvenes que son un desastre, salen a bailar y se olvidan de sus hijos. Tito, por ejemplo, no duda en expresar que estas mujeres producen bochorno porque en las bailantas "gastan el poco dinero que tienen, y tratan de comprar cariños y besos" (comunicación personal, 6 de junio de 2007).

Se sostiene, además, que ellas llaman la atención, que se ven peor que un varón. Se menciona que una cosa es ver a un hombre mareado, pero jver a una mujer mareada! [es peor]. Es decir, no causan sorpresa las relaciones extramatrimoniales de ellos, ni verlos tratando de seducir a una joven. Tampoco sorprende ver a un hombre alcoholizado. La sorpresa y el repudio aparecen cuando es una mujer quien lo hace. Si bien, como dijimos, esa mayor sorpresa que causan las mujeres se debe a que sobre ellas opera una organización sexo-genérica heteropatriarcal, también indica que el accionar de algunas está poniendo en cuestión lo socialmente esperado, es decir, lo prescripto por dicha 
organización. Ellas hacen visible que algunos de los papeles socialmente asignados a los varones, como el de la seducción, son también posibles para las mujeres. ${ }^{11}$

En otros contextos se han realizado hallazgos similares. Pedone (2008) refiere que en el contexto de migraciones femeninas en Ecuador también se ha construido una visión homogénea y estigmatizante de "las mujeres de la migración" que abandonarían a los hijos. Incluso, indica la autora, las instituciones comprometidas con el trabajo de base en el hecho migratorio han reafirmado esa visión, exaltando los peligros que corre la mujer al migrar, la posibilidad del abandono del hogar y de sus hijos e hijas. Marroni (2006) también da cuenta de la existencia de un imaginario similar asociado a las mujeres campesinas mexicanas, el cual supone que quienes migran "van de locochonas" o "andan de locas".

Durante el trabajo de campo con las mujeres peruanas documentamos su gran preocupación ante estos rumores que las estigmatizan y culpabilizan. Por temor a ser calificadas como "malas mujeres" o "malas madres" por sus parientes o hijos, algunas prefirieron reunificarse con sus esposos violentos. A resultados similares llegaron Skolnik et al. (2012), quienes encontraron que, en comparación con los varones, las mujeres guatemaltecas toman más medidas preventivas para evitar ser "chismorreadas" y se ven más afectadas negativamente por los efectos de los chismes transnacionales. Las autoras enfatizan la naturaleza altamente generizada del chisme transnacional, que potencialmente puede reforzar las relaciones patriarcales. De hecho, el aumento de la ansiedad, la depresión y el aislamiento entre las mujeres puede considerarse un subproducto de la facilidad con que corren los rumores y chismes de un país a otro.

\section{LA FUNCIÓN DE LOS IMAGINARIOS Y DE LOS RUMORES TRANSNACIONALES}

Mediante la difusión de rumores las sociedades reafirman imaginarios instituidos, se proyectan hacia lo instituyente y elaboran advertencias. Siguiendo a Canessa (2008) decimos que estos imaginarios y los rumores asociados señalan una verdad, y no una verdad que resida necesariamente en el comportamiento sexual de los y las migrantes, sino en las ansiedades que su posibilidad suscita. Entonces, como lo señalamos en la introducción, la verdad de los rumores no puede ser juzgada por su contenido, sino por su valor pragmático y por la moral que sugiere. Su verdad, indica Rouquette (2009), es ser el signo de un espanto o de un desposeimiento. En efecto, consideramos que los rumores analizados expresan el "espanto" ante la posible "transgresión" de morales hegemónicas. Pero expresan también un "desposeimiento", el del control directo. Es decir, el rumor es la

${ }^{11}$ Al identificar interseccionalmente distintas clasificaciones sociales de desigualdad no sólo se revelan lógicas de dominación sino que también se visibilizan las resistencias que las personas despliegan (Magliano, 2015). 
forma -transnacional, en este caso- que adquiere el control cuando no se lo puede ejercer directamente.

Según Fressard (2006), los imaginarios sociales orientan el decir, la acción, el sentir, el desear, así como las maneras de pensar. También los rumores sugieren "una norma de acción (no ir a tal lugar, no comprar tal producto, tomar tal precaución...). Ésta proporciona entonces cierto dominio a partir de la evitación" (Rouquette, 2009, pp. 160-161). Lo mismo se ha dicho con respecto al chisme. Skolnik et al. (2012) mencionan que cuando un grupo se siente amenazado, los chismes aumentan. Para las autoras, hablar negativamente sobre los comportamientos considerados inadecuados es una manera de aclarar qué comportamientos son apropiados y así reafirmar la identidad del grupo. Al estigmatizar ciertas acciones, se busca evitarlas e instituir "normalidades". En las dos corrientes migratorias analizadas en este escrito observamos que los rumores y los chismes buscan instituir la monogamia y el control de la sexualidad femenina, la obligación por sobre el divertimento y el placer, el trabajo por sobre el deseo, así como invalidar los entrecruzamientos sexuales interetarios, interétnicos y entre clases sociales. Así, rumores y chismes actúan proporcionando confirmación y refuerzo de la brújula de la moral colectiva dominante (Wert \& Salovey, 2004).

Wade (2008, p. 50) menciona que las mujeres figuran en los discursos nacionalistas como guardianes y civilizadoras, "pero pueden ser vistas también como una amenaza posible del cuerpo de la nación si no se comportan bien -sobre todo en lo relacionado con el sexo-. La idea de "comportarse bien" muchas veces implica mantener relaciones en su grupo o categoría social". Lo expresado por Wade permite, en primer lugar, comprender que nuestros hallazgos no aluden solamente a un tipo de control ejercido al interior de las familias o de las parejas. Estos imaginarios expresan ansiedades que trascienden las comunidades migrantes, y que responden a órdenes socioculturales, políticos y económicos mayores. En segundo lugar, se comprende que los varones migrantes pueden también ser vistos como una amenaza para el cuerpo de la nación en lo vinculado a su sexualidad y, por eso, también son objeto de rumores transnacionales. Los Estados-nación de origen y destino esperan que los varones migrantes, al igual que las mujeres, se "comporten bien", trabajen productivamente, envíen remesas, sostengan a su familia y mantengan relaciones sexuales con los de su mismo grupo. Es por ello que mediante el rumor se sanciona preventivamente (denigrando por anticipado) a quienes pudieran actuar en contrario.

En este artículo otorgamos relevancia al análisis del control de la sexualidad a través de los rumores transnacionales que provienen de imaginarios sedimentados. Sin embargo, ese énfasis no debe generar la sensación de que no existen posibilidades de resistencia, o de que los y las migrantes tienen vedado el acceso al placer y al erotismo. Aquí expusimos que, en diferentes grados, varones y mujeres migrantes disputan valores y normalizaciones. De hecho, los rumores que han sido objeto de reflexión en las páginas anteriores, al mismo 
tiempo que pueden ser concebidos como controles preventivos, reflejan las grietas del control.

También hay que decir que, si bien preocupa a los migrantes lo que se diga de ellos y se molesten ante la exageración contenida en los imaginarios sobre su sexualidad, algunos de los varones migrantes no desactivan el rumor, sino que más bien lo refuerzan. Ello se explica porque el rumor puede tener también una función de mejora de la autoimagen. En ciertos casos, en la soledad que resulta de la experiencia en la sociedad de destino, el rumor sobre ser sexualmente deseado y tener mucha actividad sexual puede ayudar a elevar, como máscara, la estima propia.

\section{REFLEXIONES FINALES}

En las secciones anteriores analizamos las características de los imaginarios que circulan en las comunidades transnacionales alrededor de la sexualidad de quienes migran. Abordamos el caso de los varones mexicanos migrantes en la ciudad de Chicago, Estados Unidos, y de las mujeres peruanas que se destinan en Buenos Aires, Argentina.

Los imaginarios analizados condensan una serie de supuestos acerca de las sociedades de destino (a las que se supone menos rígidas en materia sexual, con más equidad de género, y que brindan mayor anonimato y libertad que las de origen) y de los migrantes (supuestos en frecuente búsqueda sexual, erotizados, como potenciales abandonadores de sus familias, y con acceso a sujetos nacionales, bellos, blancos y de mejor posición socioeconómica). Estos imaginarios operan tanto sobre los varones mexicanos como sobre las mujeres peruanas. Por eso, dado que ello también ha sido encontrado en contextos migratorios diferentes a los que nosotros estudiamos, puede conjeturarse que se trata de un aspecto extendido que acompaña los movimientos migratorios contemporáneos de latinoamericanos.

Ahora bien, los imaginarios analizados tienen una mayor carga estigmatizante cuando aluden a las mujeres migrantes, en particular a quienes han migrado sin sus hijos, lo cual es coherente con la socialización sexo-genérica que prevalece en América Latina. Es decir, los imaginarios y los rumores tienen una gran carga heteropatriarcal, además de racista y clasista. Así, identificando la articulación entre distintas clasificaciones de desigualdad presentes tanto en los lugares de origen como de destino, hemos procurado recuperar una perspectiva transnacional e interseccional en relación a la construcción y operatoria de los imaginarios y rumores en la vida de las y los migrantes, y en la propia configuración de los procesos migratorios. Si bien en este artículo pusimos énfasis en las lógicas de dominación, también dimos cuenta de la agencia y la transgresión delatadas en la mera existencia de los rumores.

Por otra parte, mostramos que aunque las sociedades de origen y destino son heterogéneas en su interior, los imaginarios operan uniformizando a cada una y obviando 
sus complejidades. Al mismo tiempo, exageran las diferencias y minimizan las similitudes entre ellas, de modo que las producen como antagónicas. Algo similar sucede con la figura del migrante. Los imaginarios producen una mitificación de esa figura y la convierten en antagónica a la figura del no migrante. De tal suerte que la vida sexual de las mujeres migrantes es representada distinta a la que ellas mismas llevaron cuando no eran migrantes; y lo mismo sucede con los varones.

Teniendo en cuenta lo anterior, en este escrito hemos insistido tanto en la importancia de atender las simplificaciones que operan en los imaginarios, como en el reconocimiento de su carácter simbólico y en la necesidad de desnaturalizar sus contenidos. En efecto, "la tendencia a sustancializar la diferencia cultural reclama, desde un enfoque crítico, un análisis profundo que se nutra de datos contextuales e históricos y observe la cultura como entramado de prácticas sociales, atravesadas por el poder" (Gregorio Gil, 2009, p. 47). En este sentido, este artículo brinda elementos que permiten cuestionar los análisis reduccionistas que jerarquizan a los contextos de origen y destino con un gradiente de modernidad.

Finalmente, en las páginas anteriores discutimos la función de los imaginarios y rumores transnacionales. Hemos dicho que los mismos expresan las inquietudes que surgen en el marco del proceso migratorio ante la posibilidad de que se transgredan las fronteras normativas impuestas por la organización heteropatriarcal de la sexualidad y del género, pero también las impuestas por las construcciones raciales y la estructura de clases, entre otras. Es decir, expresan una tensión entre regulación y transformación social, y tienen la función de controlar la sexualidad a la distancia, a partir de veladas sanciones morales.

\section{REFERENCIAS}

Atkinson, R. (1998). The Life Story Interview. Thousand Oaks, Ca: SAGE Publications.

Baeza, M. A. (2011). Elementos básicos de una teoría fenomenológica de los imaginarios sociales. En J. Coca, J. Valero, F. Randazzo y J. L. Pintos, Nuevas posibilidades de los imaginarios sociales (pp. 31-42). Badajoz: Tremn-Ceasga.

Bozon, M. (2009). Sociologie de la sexualité. (2 ${ }^{\text {a }}$ Edición). París: Armand Colin.

Bron, A. y Thunborg, C, (2015). Biographical interviewing: The case of non-traditional students in higher education. SAGE Research Methods Cases. doi:10.4135/978144627305014549309

Bronfman, M. y Minello, N. (1999). Hábitos sexuales de los migrantes temporales mexicanos a los Estados Unidos de América. Prácticas de riesgo para la infección por VIH. En M. Bronfman, A. Amuchástegui, R. M. Martina, N. Minello, M. Rivas y G. Rodríguez (Eds.), Sida en México. Migración, adolescencia y género (pp. 1-90). (2da. Edición). México: Colectivo Sol. 
Caballero, M., R., Leyva-Flores, S.C., Ochoa-Marín, A., Zarco y Guerrero, C. (2008). Las mujeres que se quedan: migración e implicación en los procesos de búsqueda de atención de servicios de salud. Salud Pública de México, 50, 241-250. http://dx.doi.org/10.1590/S0036-36342008000300008.

Canessa, A. (2008). El sexo y el ciudadano: Barbies y reinas de belleza en la era de Evo Morales. En P. Wade, F. Urrea \& M. Viveros Vigoya, Raza, etnicidad y sexualidades: ciudadanía y multiculturalismo en América latina (pp. 69-104). Bogotá: Centro de Estudios Sociales/Universidad Nacional de Colombia.

Cantú, L. (2009). The Sexuality of Migration. Border Crossings and Mexican Immigrant Men. Nueva York: New York University Press.

Cohen, D. (2015). Sex, Loyalty, and Betrayal: Migration and the Limits of Patriarchal Privilege. IdeAs. Idées d'Amériques (6), doi: 10.4000/ideas.1295. Recuperado de: http://journals.openedition.org/ideas/1295

Córdova Quero, H. (2014). "Made in Brazil? Sexuality, Intimacy, and Identity Formation among Japanese Brazilian Queer Immigrants in Japan” En H. Córdova Quero, J. N. Goh y M. Sepidoza Campos (Eds.). Queering Migrations Towards, From, and Beyond Asia (pp. 41-59). Nueva York: Palgrave Macmillan. doi: 10.1057/9781137447739_3

Cribari, L., Pandolfi, M. J. y Torre, V. (2012). ¿Exilio sexual? Un viaje por nuevas rutas identitarias. Crítica Contemporánea. Revista de Teoría Política, (2), 154-177.

D'Aubeterre Buznego, M. E. (2000). El pago de la novia: matrimonio, vida conyugal y prácticas transnacionales en San Miguel Acuexcomac, Puebla. Zamora, México: El Colegio de Michoacán/Instituto de Ciencias Sociales y Humanidades de la Benemérita Universidad Autónoma de Puebla.

Delgadillo Guzmán, L. G., A., Vargas Cortez, A., Nievar, Á., Argüello Zepeda, J. F. y González Villanueva (2013). Efectos de la violencia de pareja en mujeres migrantes. Civilizar Ciencias Sociales y Humanas, 13(24), 103-116.

DiFonzo N. y Bordia, P. (2007). Rumor, Gossip and Urban Legends. Diogenes, 54(1), 1935. doi: $10.1177 / 0392192107073433$

Dreby, J. (2009). Gender and Transnational Gossip. Qualitative Sociology, 32(1), 33-52. doi:10.1007/s11133-008-9117-x

Escobar Villegas, J. C. (2000). Lo imaginario: entre las ciencias sociales y la historia. Medellín: Fondo Editorial Universidad EAFIT.

Esguerra Muelle, C. (2014). Dislocación y borderland: Una mirada oblicua desde el feminismo descolonial al entramado migración, régimen heterosexual, (pos)colonialidad y globalización. Universitas Humanística, (78), 137-161. doi:10.11144/Javeriana.UH78.dbmo 
Fressard, O. (2006). El imaginario social o la potencia de inventar de los pueblos. Transversales, (2). http://www.trasversales.net/t02olfre.htm

García Canclini, N. (1997). Imaginarios urbanos. Buenos Aires: EUDEBA.

García, A. A. y Oñate Martínez, S. (2008). Transexuales ecuatorianas: el viaje y el cuerpo. En G. Herrera y J. Ramírez (Eds.). América Latina migrante: Estado, familias, identidades (pp. 343-360). Quito: Facultad Latinoamericana de Ciencias Sociales-Sede Ecuador/Ministerio de Cultura del Ecuador.

Gayet C. (2015). Infecciones de transmisión sexual en México: una mirada desde la historia y el género. México: Censida.

Gayet, C., Magis, C. y Bronfman, M. (2000). Aspectos conceptuales sobre la relación entre migración y SIDA en México. Enfermedades Infecciosas y Microbiología Clínica, 20(4), 134-140.

González-López, G. (2009). Travesías eróticas. La vida sexual de mujeres y hombres migrantes de México. México: Instituto Nacional de Migración/Miguel Ángel Porrúa.

Gonzálvez, H. (2014). Repensar la sexualidad desde el campo migratorio: una etnografía multisituada sobre parejas heterosexuales migrantes colombianas. Revista de Estudios Sociales, (49), 101-112. doi:10.7440/res49.2014.08

Gregorio Gil, C. (2009). Mujeres inmigrantes: Colonizando sus cuerpos mediante fronteras procreativas, étnico-culturales, sexuales y reproductivas. Viento Sur, (104), 42-54. Recuperado de: http://cdn.vientosur.info/VScompletos/vs_0104.pdf

Hernández-Hernández, O. (2015). Sexualidades Transnacionales. Varones y mujeres migrantes en Estados Unidos y México. En J. M. Valcuende del Río, P. Vásquez Andrade y M. J. Marco Macarro (coords.). Sexualidades: Represión, resistencia y cotidianidades (pp. 409-423). Sevilla, España: Aconcagua Libros.

Hidalgo, I., García, F., Flores, A., Castañeda, X. Lemp, J. y Ruiz, J. (2008). Aquí y en el otro lado. Los significados socioculturales de la sexualidad y sus impactos en la salud sexual de los migrantes mexicanos. Revista Migraciones Internacionales, 5(3), 27-49.

Hirsch, J. S. (1999). En el norte la mujer manda gender, generation, and geography in a Mexican transnational community. American Behavioral Scientist, 42(9), 1332-1349.

Hoagland, S. L. (2002). What is 'heteropatriarchy'? En L. Code (Ed.), Encyclopedia of feminist theories (p. 245). Nueva York: Routledge.

Luibhéid, E. y Cantú Jr. L. (Eds.) (2005). Queer migrations: Sexuality, US citizenship, and border crossings. Minneapolis: University of Minnesota Press.

Magis-Rodríguez, C., Gayet, C., Negroni, M., Leyva, R., Bravo-García, E., Uribe, P. y Bronfman, M. (2004). Migration and AIDS in Mexico: an overview based on recent 
evidence. JAIDS Journal of Acquired Immune Deficiency Syndromes, 37, S215-S226. doi: 10.1097/01.qai.0000141252.16099.af

Magliano, M. J., (2015). Interseccionalidad y migraciones: potencialidades y desafíos. Estudos Feministas, 23(3), 691-712. doi: 10.1590/0104-026X2015v23n3p691

Manalansan, M. (2006). Queer Intersections: Sexuality and Gender in Migration Studies The International Migration Review, 40(1), 224-249. doi: 10.1111/j.17477379.2006.00009.x

Marroni, M. D. (2006). Migrantes mexicanas en los escenarios familiares de las comunidades de origen: amor, desamor y dolor. Estudios Sociológicos, 24(72), 667-699. Recuperado de: http://estudiossociologicos.colmex.mx/index.php/es/article/view/410/410

Martinez-Donate, A. P., Hovell, M. F., Rangel, M. G., Zhang, X., Sipan, C. L., MagisRodriguez, C. y González-Fagoaga, J. E. (2015). Migrants in transit: the importance of monitoring HIV risk among migrant flows at the Mexico-US border. American Journal of Public Health, 105(3):497-509. doi: 10.2105/AJPH.2014.302336

Nyberg Sørensen, N. y Vammen, I. M. (2016). ¿A quién le importa? Las familias transnacionales en los debates sobre la migración y el desarrollo. Investigaciones Feministas, 7(1), 191-220. doi:10.5209/rev_INFE.2016.v7.n1.52707

Ochoa-Marín S., Cristancho-Marulanda S., González-López J.R. (2011). Mujeres compañeras de migrantes: imagen social y búsqueda de servicios de salud sexual y reproductiva. Revista de salud pública, 13(2), 183-195. doi: 10.1590/S012400642011000200001

Pedone, C. (2008). "Varones aventureros" vs. "madres que abandonan": Reconstrucción de las relaciones familiares a partir de la migración ecuatoriana. Revista Interdisciplinar da Mobilidade Humana, XVI(30), 45-64.

Pedone, C. (2003). "Tú siempre jalas a los tuyos". Las cadenas y las redes migratorias de las familias ecuatorianas hacia España. (Tesis de doctorado). Universitat Autónoma de Barcelona. Departament de Geografia. Recuperado de: http://www.tdx.cat/handle/10803/4956?show=full

Pérez Oseguera, M. L., Coppe Gorozope, L., Pérez Petrone, T. y Trujillo Viruega, T. (2008). Mujeres migrantes y violencia. Revista Internacional de Ciencias Sociales y Humanidades, SOCIOTAM, vol. XVIII(1), 229-250. Recuperado de http://www.redalyc.org/articulo.oa?id=65411190011

Pichardo Galán, J. I. (2003). Migraciones y opción sexual. En O. Guasch y O. Viñuales (coords.). Sexualidades. Diversidad y control social (pp. 277-297). Barcelona: Bellaterra. 
Piscitelli, A. (2008). Interseccionalidades, categorias de articulação e experiências de migrantes brasileiras. Sociedade e Cultura, 11(2), 263-274. doi: 10.5216/sec.v11i2.5247

Quispe-Lázaro, A. y Muñoz-Laboy, M. (2008). Como uno es hombre... es difícil abstenerse: organización social del riesgo sexual entre migrantes mexicanos en Nueva York. En G. Careaga, Memorias del 1er. Encuentro Latinoamericano y del Caribe La sexualidad frente a la sociedad (pp. 76-109). México: Fundación Arcoiris.

Rivera-Heredia, M. E., Obregón Velasco, N. y Cervantes Pacheco, E. I. (2013). Migración, sucesos estresantes y salud: perspectivas de las mujeres michoacanas de comunidades rurales con familiares migrantes. Acta Universitaria, 23(1) pp. 49-58. Recuperado de: http:/oaji.net/articles/2014/563-1396295204.pdf

Rosas, C. (2013). Discusiones, voces y silencios en torno a las migraciones de mujeres y varones latinoamericanos. Notas para una agenda analítica y política. Anuario Americanista Europeo, 127-148.

Rosas, C. (2010). Implicaciones mutuas entre el género y la migración. Varones y mujeres peruanos arribados a Buenos Aires entre 1990 y 2003. Buenos Aires: Eudeba.

Rosas, C. (2008). Varones al son de la migración. Migración internacional y masculinidades de Veracruz a Chicago. México: El Colegio de México.

Rouquette, M. L. (2009). Los rumores y la cuestión de la verdad. Versión, 23, 157-166.

Ruiz, M. C. (2008). Migración transfronteriza y comercio sexual en Ecuador: condiciones de trabajo y las percepciones de las mujeres migrantes. En G. Herrera y J. Ramírez (Eds.) América Latina migrante: Estado, familia, identidades (pp. 201-221). Quito: Facultad Latinoamericana de Ciencias Sociales (FLACSO)-Sede Ecuador/Ministerio de Cultura del Ecuador.

Salgado de Snyder, N. (1998). Migración, sexualidad y SIDA en mujeres de origen rural: sus implicaciones psicosociales. En I. Szasz y S. Lerner (Comps). Sexualidades en México. Algunas aproximaciones desde la perspectiva de las ciencias sociales (pp. 155171). México: El Colegio de México.

Skolnik, J., De La Vega, S. L. \& Steigenga, T. (2012). Chisme across borders: The impact of gossip in a Guatemalan transnational community. Migraciones Internacionales, 6(3), 9-38. doi 10.17428/rmi.v6i22.738

Stang, M. F. (2015). La familia como frontera. Algunos indicios para re-pensar la relación entre migración y familia en un caso de migración intrarregional LGTBI. I Simposio de la Sección de Estudios del Cono Sur (LASA), Chile 2015. Inédito.

Stolcke, V. (2010). ¿Qué tiene que ver el género con el parentesco? En V. Fons, A. Piella y M. Valdés (Eds.). Procreación, crianza y género. Aproximaciones antropológicas a la parentalidad (pp. 319-334). Barcelona: Promociones y Publicaciones Universitarias. 
Vidal Ortiz, S. (2013). Más allá de la nación: la sexualidad y el género como ejes centrales de migración. Maguaré, 27(1), 195-213. Recuperado de: http://revistas.unal.edu.co/index.php/maguare/article/view/43228/44533

Wade, P. (2008). Debates contemporáneos sobre raza, etnicidad, género y sexualidad en las ciencias sociales. En P. Wade, F. Urrea \& M. Viveros Vigoya, Raza, etnicidad y sexualidades: ciudadanía y multiculturalismo en América Latina (págs. 41-66). Bogotá: Centro de Estudios Sociales-Universidad Nacional de Colombia.

Wert, S. R. y Salovey, P. (2004). A social comparison account of gossip. Review of General Psychology, 8(2), 122. doi:10.1037/1089-2680.8.2.122

Zires, M. (2009). Rumor: Voces del tejido social. Versión, 23, 8-13. 